\title{
Efeito da composição granulométrica e da área superficial específica de resíduos de polimento de porcelanato em argamassas autoadensáveis
}

\author{
Effects of particle size and specific surface area of \\ porcelain tile polishing waste on self-compacting mortars
}

\author{
Andrea Murillo Betioli \\ Morgana Fortunato \\ Ben-Hur Raíra Martins \\ Juliana Machado Casali \\ Janaíde Cavalcante Rocha \\ Giovana Collodetti
}

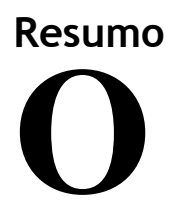

desenvolvimento de novas tecnologias e o incentivo ao

reaproveitamento de resíduos vêm crescendo em função da redução

dos prazos nas construções e da preocupação com o meio ambiente. $\mathrm{O}$ objetivo deste trabalho foi avaliar a influência da adição de resíduo de polimento de porcelanato (RPP) proveniente de dois lotes de uma empresa em argamassas autoadensáveis. Foram mantidos constantes a relação água/cimento e os teores de aditivos para cada porcentagem de adição de RPP. Observou-se que a granulometria e a área superficial específica afetaram a fluidez e as propriedades mecânicas. A adição do RPP0 (menor área superficial específica e partículas mais grossas) resultou em menor teor de ar incorporado e o aumento de resistência a partir de 10\% de adição. Já, o RPP1 (área superficial específica maior e partículas mais finas) diminuiu a fluidez das argamassas mantendo alto o teor de ar incorporado, resultando em ganhos menores de resistência à compressão. Os

${ }^{1}$ Andrea MurilloBetioli ${ }^{1}$ Instituto Federal de Santa Catarina Florianópolis - SC - Brasil ${ }^{2}$ Morgana Fortunato
${ }^{2}$ Instituto Federal de Santa Catarina
Florianópolis - SC - Brasil

${ }^{3}$ Ben-HurRaíra Martins ${ }^{3}$ Instituto Federal de Santa Catarina Florianópolis - SC - Brasil

${ }^{4} J u l i a n a$ Machado Casali ${ }^{4}$ Instituto Federal de Santa Catarina Florianópolis - SC - Brasil

${ }^{5}$ Janaíde Cavalcante Rocha
${ }^{5}$ Universidade Federal de Santa
Catarina
Florianópolis - SC - Brasil

${ }^{6}$ Giovana Collodetti ${ }^{6}$ Instituto Federal de Santa Catarina Florianópolis - SC - Brasil

Recebido em 24/09/19 resultados demonstraram que a influência do teor ar incorporado prevaleceu sobre a possível melhora no empacotamento das partículas e o efeito de nucleação. No entanto, independente do teor e tipo de RPP utilizado, os resultados viabilizaram o uso desses finos em argamassas autoadensáveis.

Palavras-chave: Argamassa autoadensável. Resíduo de polimento de porcelanato. Sustentabilidade.

\section{Abstract}

Current demands for shorter construction times and concerns about mitigating environmental impact are leading to the development of new technologies and encouraging waste recycling. The aim of this paper was to evaluate the influence of the addition of porcelain tile polishing waste (PTPW) from two lots of the same factory in self-compacting mortar production. The water to cement ratio and the additive content were maintained the same. The results show that the PTPW grain particle size and specific surface area affected the mortars' flowability and mechanical properties. Mortars with PTPWO (thicker particles than PTPW1) presented increased compressive strength and a reduced air entrained, already from a $10 \%$ addition. In turn, the addition of PTPW1 led to a decrease in the flowability of the mortars, maintaining a high rate of air entrained, which resulted in a lower gain of compressive strength. The results showed that the influence of the air-entrained rate on the compressive strength of the mortars prevailed over any possible improvements in particle packing and nucleation effects. Nonetheless, regardless of the amount and type of PTPW used, the study shows the viability of using it to produce satisfactory self-compacting mortars.

Aceito em 13/04/20 Keywords: Self-compactingmortar. Porcelain tile polishing waste. Sustainability. 


\section{Introdução}

No mercado da construção civil existe atualmente uma crescente aceleração dos prazos no cronograma das obras. Há uma valorização por obras mais limpas e com industrialização nos canteiros de obras. Com isso, o desenvolvimento de novas tecnologias é cada vez mais comum e necessário. Um exemplo é o uso de argamassas autoadensáveis para a execução de contrapisos. Inúmeras são as vantagens dessa argamassa: redução no consumo de cimento Portland e peso próprio pela execução de pequena espessura; redução de mão de obra e de tempo de execução; horizontalidade sem necessidade de desempeno; menor chance de patologias, entre outras (MARTINS, 2009).

A argamassa autoadensável é um material relativamente novo no Brasil e começou a ser estudada por empresas de construção civil e pesquisadores no início de 2008 (MARTINS, 2009). Alguns pesquisadores indicam que, para se obter essa argamassa, deve-se utilizar cimento Portland de alta resistência inicial (25\% a $50 \%$ da massa total), areia fina quartzosa (40\% a 60\%), 20\% a 30\% de água em relação à massa seca total da mistura e o restante por adições e aditivos (NAKAKURA; BUCHER, 1997). Porém, o alto consumo de cimento Portland, necessário para a fluidez desse tipo de argamassa, pode acarretar fissuração no contrapiso, além de gerar impactos ambientais, uma vez que, para a produção de $1 \mathrm{t}$ de cimento Portland, são emitidas de $0,8 \mathrm{t}$ a $1 \mathrm{t}$ de $\mathrm{CO}_{2}$. Ressalta-se que a indústria cimenteira é responsável por cerca de $5 \%$ de todas as emissões de $\mathrm{CO}_{2}$ (WORLD..., 2017).

Desse modo, a substituição do cimento Portland por uma adição mineral pode evitar ou diminuir a retração ocasionada pelo cimento Portland (CARVALHO, 2015) e reduzir o impacto ambiental gerado por ele. Essa adição poderia ser um subproduto industrial (siderúrgico, termoelétrico, alimentício, produção de agregados, etc.) finamente particulado, um material inerte ou com características aglomerantes, sendo os mais comuns o fíler calcário, a cinza volante, o metacaulim, a escória de alto-forno e a sílica ativa. As vantagens da utilização das adições aos materiais à base de cimento Portland podem ser:

(a) econômicas, pela redução no consumo de cimento Portland (geralmente o componente mais caro);

(b) tecnológicas, pela melhoria nas propriedades do estado fresco, na resistência mecânica e na durabilidade; e

(c) ambientais, pela destinação ou reaproveitamento correto dos resíduos industriais e redução da emissão de $\mathrm{CO}_{2}$ (liberado na produção do cimento Portland) (DAL MOLIN, 2011).

Assim, pelas vantagens ambientais, uma das propostas de utilização é o resíduo do polimento de porcelanato (RPP). Durante a etapa de polimento são gerados cerca de $100 \mathrm{~g}$ de RPP por metro quadrado de porcelanato (JACOBY; PELISSER, 2015). A produção anual de porcelanato é de 152 milhões de metros quadrados, portanto se estima uma geração anual de 15.200 mil toneladas de RPP no Brasil, segundo a Anfacer (ASSOCIAÇÃO..., 2019). Atualmente, muito pouco é aproveitado na própria indústria cerâmica, sendo sua disposição final geralmente feita em aterros controlados (KUMMER et al., 2007). Para a destinação desse resíduo, o RPP é classificado como resíduo Classe II A - Não inerte, ou seja, um resíduo não danoso que pode apresentar propriedades como biodegradabilidade, combustibilidade ou solubilidade em água, segundo a classificação de resíduos sólidos (ABNT, 2004).

O RPP é um material finamente particulado proveniente do desgaste superficial das peças, composto basicamente da própria cerâmica, além de uma pequena contribuição de outros compostos oriundos do polimento e do tratamento do resíduo (ANDREOLA et al., 2010). Atualmente, o RPP não é reutilizado em grande escala, mas o que se tem observado é um aumento nas pesquisas com o intuito de avaliar o potencial de utilização desse resíduo em materiais cimentícios, como no caso da argamassa de revestimento (SOUZA, 2013), bloco de concreto (STEINER, 2011), concreto (SILVA, 2005; SOUZA, 2007), concreto autoadensável (MATOS et al., 2018) e como material cimentício suplementar (PELISSER; STEINER; BERNARDIN, 2012; STEINER, 2014; STEINER; BERNARDIN; PELISSER, 2015; JACOBY; PELISSER, 2015).

Steiner, Bernardin e Pelisser (2015) avaliaram o RPP como material cimentício suplementar e, substituindo o cimento Portland por RPP, observaram que o resíduo manteve a consistência das argamassas e apresentou elevado índice de atividade pozolânica, melhorando o índice de eficiência de consumo de cimento Portland $\left(\mathrm{em} \mathrm{kg} / \mathrm{m}^{3} / \mathrm{MPa}\right)$, reduzindo-o em torno de $30 \%$. Os autores também verificaram que a adição do RPP, além de aumentar o tempo para o início das retrações, reduziu a retração autógena.

Nos estudos em concreto, Silva (2005) e Souza (2007) observaram aumento da resistência à compressão do concreto com a adição de RPP, resultado da densificação da matriz pelo efeito fíler e reações pozolânicas.

386 Betioli, A. M.; Fortunato, M.; Martins, B.-H. R.; Casali, J. M.; Rocha, J. C.; Collodetti, G. 
Jacoby e Pelisser (2011) observaram que o resíduo melhorou as características de trabalhabilidade e consistência das argamassas; também indicaram atividade pozolânica, comprovada pelo ganho de resistência à compressão, em média $50 \%$ para uma adição de $20 \%$ de RPP. Já Souza (2013) concluiu que a incorporação de até $20 \%$ de RPP em argamassa de revestimento não alterou significativamente as propriedades nos estados fresco e endurecido quando comparado à argamassa de referência, resultado do efeito fíler do RPP, uma vez que analisou em idades iniciais.

Em concretos autoadensáveis (CAA), estudos realizados por Matos et al. (2018) demonstraram que a substituição do cimento Portland por até $20 \%$ de RPP obteve desempenhos equivalentes aos da referência no estado fresco, até $95 \%$ da resistência à compressão dela aos 91 dias e até $98 \%$ aos 365 dias, explicado pelo efeito pozolânico, em idades avançadas.

A composição química do RPP avaliada por diversos autores citados por Matos (2019) demonstra, em geral, que ele é composto em sua maioria por sílica $(58,90-68,97 \%)$ e alumina $(15,49-21,04 \%)$. Além disso, sua distribuição granulométrica é ligeiramente mais fina que a do cimento Portland, com elevada superfície específica do resíduo (cerca de 10 vezes maior que a do cimento Portland) (PELISSER; STEINER; BERNARDIN, 2012). Ainda, diversos autores comprovaram a atividade pozolânica do RPP (PELISSER; STEINER; BERNARDIN, 2012; STEINER, 2014; JACOBY; PELISSER, 2015; MATOS et al., 2018).

No entanto, conforme observado por de Steiner (2014), existe variabilidade nos resultados de análise química e dos diâmetros médios entre lotes diferentes de uma mesma empresa. Assim, a distribuição granulométrica e a área superficial específica desse resíduo também devem ser analisadas, pois podem influenciar diretamente na reologia dos materiais cimentícios, sendo ainda mais importante para materiais autoadensáveis.

Dessa forma, diante do potencial de reaproveitamento desse resíduo amplamente gerado no estado de Santa Catarina e no país, este trabalho avaliou o efeito da distribuição granulométrica e da área superficial específica do RPP nas propriedades de argamassa autoadensável, visando à redução do consumo de cimento Portland, assim como à viabilidade técnica de seu emprego nessas argamassas.

\section{Materiais e métodos}

O programa experimental foi dividido em três partes. A primeira descreve os materiais utilizados, a segunda, a produção, e a terceira, os ensaios realizados nas argamassas autoadensáveis.

\section{Materiais}

As argamassas foram confeccionadas com cimento Portland composto com fíler calcário (CPII F 32), agregado miúdo (areia natural), fíler calcário, aditivo dispersante (SP) e aditivo promotor de viscosidade (VMA). A areia utilizada é uma areia média-fina, cuja granulometria encontra-se na Figura 1 e cuja caracterização física, na Tabela 1, assim como os dados do fíler calcário e do cimento Portland. A Tabela 2 traz a caracterização dos aditivos empregados.

O RPP utilizado nesta pesquisa foi coletado em uma empresa do sul de Santa Catarina. As amostras de RPP, denominadas RPP0 e RPP1, foram coletadas em dias diferentes, ao longo de 6 meses de produção. Antes dos ensaios, elas foram secas em estufa a $60 \pm 5^{\circ} \mathrm{C}$ até constância de massa e então destorroadas.

Tabela 1- Caracterização física da areia, fíler calcário e cimento Portland

\begin{tabular}{l|l|c}
\hline \multicolumn{1}{c|}{ Material } & \multicolumn{1}{|c}{ Propriedades } & Resultado \\
\hline \multirow{3}{*}{ Areia natural } & Massa específica $\left(\mathrm{g} / \mathrm{cm}^{3}\right)(\mathrm{ABNT}, 2009)$ & 2,60 \\
\cline { 2 - 3 } & Dimensão máxima característica $(\mathrm{mm})(\mathrm{ABNT}, 2003)$ & 2,36 \\
\cline { 2 - 3 } & Módulo de finura $(\mathrm{ABNT}, 2003)$ & 1,49 \\
\hline \multirow{2}{*}{ Fíler calcário } & Massa específica $\left(\mathrm{g} / \mathrm{cm}^{3}\right)(\mathrm{ABNT}, 2009)$ & 2,7 \\
\hline \multirow{2}{*}{ Cimento CP II F 32 } & Massa específica $\left(\mathrm{g} / \mathrm{cm}^{3}\right)(\mathrm{ABNT}, 2017)$ & 3,07 \\
\cline { 2 - 3 } & Área superficial específica $\left(\mathrm{m}^{2} / \mathrm{g}\right)$ & 0,98 \\
\hline
\end{tabular}


Figura 1 - Distribuição granulométrica da areia

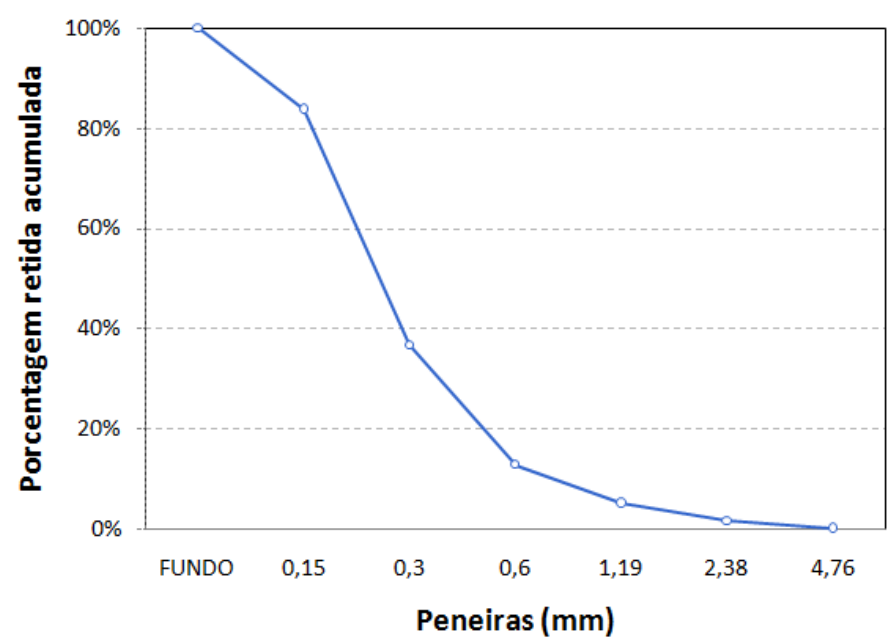

Tabela 2- Características dos aditivos utilizados

\begin{tabular}{l|l|c|c|l}
\hline \multirow{2}{*}{ Aditivos } & \multicolumn{4}{|c}{ Dados Técnicos } \\
\cline { 2 - 5 } & \multicolumn{1}{|c|}{ Características } & Unidade & Valor & \multicolumn{1}{c}{ Observações } \\
\hline \multirow{2}{*}{ SP } & Densidade & $\mathrm{g} / \mathrm{cm}^{3}$ & 1,12 & - \\
\cline { 2 - 5 } & Dosagem recomendada & $\%$ & 0,2 a 5 & Dosagem em relação à massa de cimento \\
\hline \multirow{2}{*}{ VMA } & Densidade & $\mathrm{g} / \mathrm{cm}^{3}$ & 1,00 & - \\
\cline { 2 - 5 } & Dosagem recomendada & $\%$ & 0,1 a 1,5 & Dosagem em relação à massa de cimento \\
\hline
\end{tabular}

Fonte: resultados obtidos com o fabricante dos aditivos.

As distribuições granulométricas foram realizadas em granulômetro a laser Helos (Sympatec) com faixa de detecção $0,1 \mu \mathrm{m}$ a $350 \mu \mathrm{m}$, conforme mostra a Figura 2. Observa-se que o RPP é um material mais fino que o cimento Portland e o fíler. Ressalta-se a diferença das granulometrias para os diferentes RPP coletados numa mesma empresa, diferentemente do observado por Steiner (2014). Observa-se que o RPP0 apresenta quantidade maior de partículas mais grossas, o que vai refletir em sua área superficial específica, descrita adiante.

O diâmetro médio (D50) das duas amostras de RPP (RPP0 8,8 $\mu \mathrm{m}$ e RPP1 7,9 $\mu \mathrm{m}$ ) são inferiores aos do cimento Portland $(15,8 \mu \mathrm{m})$ e do fíler calcário $(21,5 \mu \mathrm{m})$, e estão dentro dos limites apresentados por Pelisser, Steiner e Bernardin (2012) e Matos et al. (2018).

Em relação ao material retido na peneira de $45 \mu \mathrm{m}$, os resultados evidenciam uma possível atividade pozolânica conforme as normas C618 (AMERICAN..., 2012) e NBR 12653 (ABNT, 2015), quando o material retido na peneira $45 \mu \mathrm{m}$ deve ser $\leq 34 \%$ e $\leq 20 \%$ respectivamente, o que é corroborado pela análise química na Tabela 3 e comprovado por Matos et al. (2018), que utilizaram o RPP da mesma empresa em sua pesquisa.

A área superficial específica (ASE) foi determinada em um equipamento Belsorp Max, com pré-tratamento das amostras em temperatura de $60{ }^{\circ} \mathrm{C}$ e pressão de $10^{-2} \mathrm{kPa}$ por $24 \mathrm{~h}$ em um equipamento Belprepvac-II para a retirada da umidade e de outros gases adsorvidos. A Tabela 3 apresenta os resultados de área superficial específica e massa específica (ABNT, 2009) dos dois RPP coletados.

A composição química dos materiais utilizados foi determinada por fluorescência de raios $\mathrm{X}$ em equipamento de análise industrial, Sorter S1, da marca Bruker, e apresentada na Tabela 4. Nota-se que a composição do cimento Portland CP II F 32 contém teores elevados de Ca e Si seguidos de $\mathrm{Al}$ e Fe, e o fíler calcário tem alto teor de cálcio, como era esperado. Nas amostras de RPP foram identificadas as maiores concentrações de $\mathrm{Si}$ e $\mathrm{Al}$, e pouca concentração de $\mathrm{Fe}, \mathrm{K}$ e $\mathrm{Ca}$, elementos característicos de materiais cerâmicos, também observado por diversos autores citados por Matos (2019), cujos valores mínimos e máximos são de 58,90\% a $68,97 \%$ de sílica e de $15,49 \%$ a $21,04 \%$ de alumina. Nota-se que os RPP desta pesquisa apresentam valores superiores de sílica.

388 Betioli, A. M.; Fortunato, M.; Martins, B.-H. R.; Casali, J. M.; Rocha, J. C.; Collodetti, G. 
Conforme comentado anteriormente, uma potencial atividade pozolânica do RPP pode ser observada pela análise química, uma vez que o somatório dos percentuais de $\mathrm{SiO}_{2}+\mathrm{Al}_{2} \mathrm{O}_{3}+\mathrm{Fe}_{2} \mathrm{O}_{3}$ é aproximadamente $91 \%$, superior aos 70\%, preconizados nas normas NBR 12653 (ABNT, 2015) e C 618 (AMERICAN..., 2012).

Para a avaliação dos componentes químicos dos dois resíduos estudados, foi realizada a difração de raios $\mathrm{X}$ em um difratômetro Shimadzu XRD 6000, tubo de raios X de cobre operando com radiação $\mathrm{Cu} \mathrm{Ka} \mathrm{(=}$ $1,5418 \hat{\mathrm{A}}$ ), tensão de $30 \mathrm{kV}$ e corrente de $15 \mathrm{~mA}$. A análise foi feita a partir de $10^{\circ}$ a $80^{\circ}(2 \theta)$ em um tempo de leitura $2 \%$ min.

Figura 2 - Curvas granulométricas obtidas por granulometria a laser do cimento Portland CP II F, do fíler calcário e dos resíduos de RPP0e RPP1
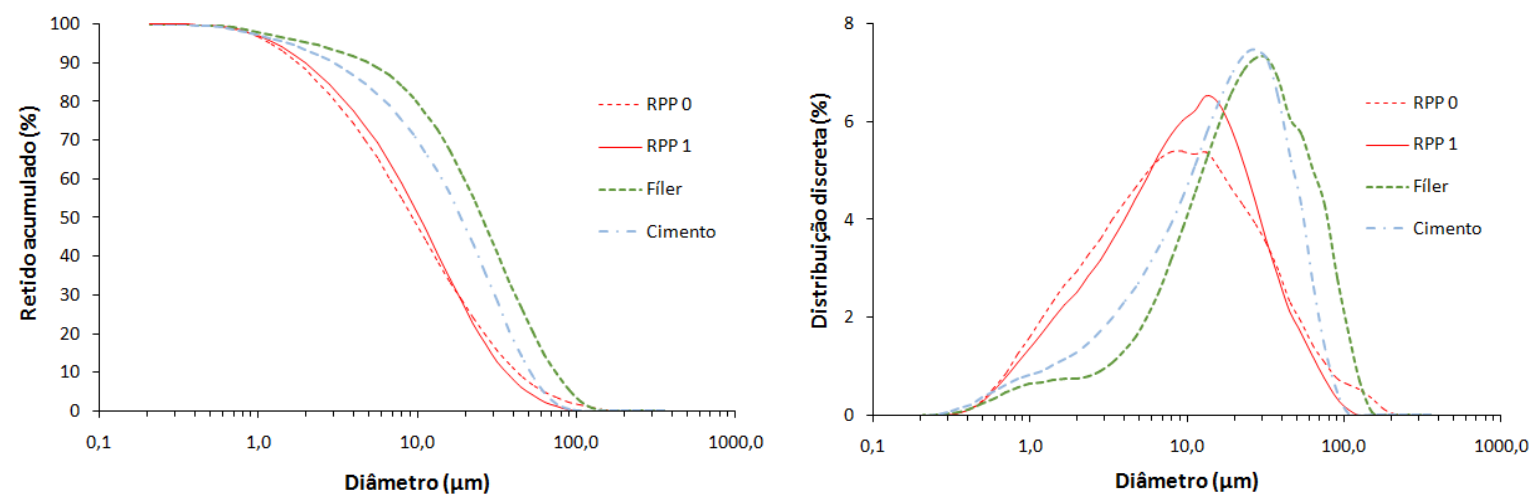

Tabela 3 - Área superficial específica e massa específica dos dois resíduos de RPP coletados

\begin{tabular}{c|c|c}
\hline Material & RPP0 & RPP1 \\
\hline Área superficial específica $\left(\mathrm{m}^{2} / \mathrm{g}\right)$ & 8,77 & 12,39 \\
Massa específica $\left(\mathrm{g} / \mathrm{cm}^{3}\right)$ & 2,31 & 2,31 \\
\hline
\end{tabular}

Tabela 4 - Análise FRX do cimento Portland CP II F, do fíler e dos resíduos de RPPO e RPP1

\begin{tabular}{c|c|c|c|c}
\hline & Cimento & Fíler & RPP0 & RPP1 \\
\hline Óxido & \multicolumn{4}{|c}{ \% } \\
\hline $\mathrm{CaO}$ & 43,62 & 53,03 & 1,33 & 1,22 \\
$\mathrm{SiO}$ & 33,24 & 4,66 & 74,00 & 72,64 \\
$\mathrm{Al}_{2} \mathrm{O}_{3}$ & 6,94 & - & 16,34 & 17,27 \\
$\mathrm{Fe}_{2} \mathrm{O}_{3}$ & 4,00 & 0,43 & 1,45 & 1,14 \\
$\mathrm{SO}_{3}$ & 3,81 & - & 0,13 & 0,14 \\
$\mathrm{~K}_{2} \mathrm{O}$ & 2,21 & 0,19 & 2,53 & 2,47 \\
$\mathrm{TiO}$ & 0,70 & 0,05 & 0,30 & 0,23 \\
$\mathrm{SrO}$ & 0,22 & 0,28 & - & - \\
$\mathrm{MnO}$ & 0,10 & 0,01 & - & - \\
$\mathrm{ZnO}$ & 0,06 & - & 0,30 & - \\
$\mathrm{ZrO}$ & - & - & 0,14 & 0,43 \\
$\mathrm{Rb}$ & - & - & 0,17 & 0,19 \\
$\mathrm{MnO}$ & - & - & 0,05 & 0,04 \\
$\mathrm{CuO}$ & - & 0,02 & 0,05 & 0,04 \\
$\mathrm{Perda}$ ao fogo & 5,00 & 41 & 3,15 & 3,92 \\
\hline
\end{tabular}


Nas Figuras 3(a) e 3(b) são mostrados os difratogramas das amostras RPP0 e RPP1, e as principais fases identificadas. Verifica-se que as fases cristalinas presentes nos materiais estão relacionadas à presença majoritariamente do quartzo $\left(\mathrm{SiO}_{2}\right)$ junto com a mulita $\left(3 \mathrm{Al}_{2} \mathrm{O}_{3} 3 \mathrm{SiO}_{2}\right)$ e fase albita $\left(\mathrm{NaAlSi}_{3} \mathrm{O}_{8}\right)$ e carbeto de silício ( $\mathrm{SiC}$ ). As fases identificadas são compatíveis com os resultados da análise dos óxidos totais, ou seja, majoritariamente formados por $\mathrm{SiO}_{2}, \mathrm{Al}_{2} \mathrm{O}_{3}$. Essas fases são originadas do processo de beneficiamento, isto é, na exposição àelevada temperatura de queima e no acabamento final, durante o polimento das peças. A presença da mulita é devidaà transformação da caulinita durante o processo de queima. Dos demais aluminossilicatos, devido à reação da caulinita com outros aditivos usados nos processos. Já o carbeto de silício está associado ao processo de polimento, conforme relatado por Bernardin et al. (2006). Pressupõe-se ainda uma possível fase vítrea pela formação de halo amorfo (ângulo $2 \Theta$ de $15^{\circ}$ a $32^{\circ}$ ), embora esse aspecto não tenha sido explorado no presente artigo. Segundo Steiner (2014), essa existência indica que o RPP é um material potencialmente reativo.

Com o intuito de avaliar a superfície e o formato dos grãos, foram feitas imagens dos grãos de RPP0 e RPP1 em microscópio eletrônico de varredura (MEV) convencional, com filamento de tungstênio, JEOL JSM6390LV (Figura 4). As amostras secas foram fixadas com fita-carbono na base do suporte do equipamento, recobertas com ouro pulverizado e mantidas em dessecador a vácuo até a data da análise. Em conjunto com a análise de imagens foi possível realizar a espectrometria de dispersão de energia (EDS), determinando a composição química aproximada de partículas, de regiões ou pontos de interesse (Figura 5).

A Figura 4 mostra as micrografias dos grãos de RPP para as ampliações de 100x (a, d), 500x (b, e) e 2.000x $(\mathrm{c}, \mathrm{f})$. Nota-se que os grãos não apresentam forma definida, sendo irregulares e angulosos, o que pode influenciar no aumento da demanda de água ou no teor do aditivo dispersante.

A microanálise usando a sonda EDS (espectroscopia por dispersão de raios X) foi realizada pontualmente nas aproximações das imagens do MEV e teve por objetivo verificar a natureza das partículas com as análises da composição dos óxidos totais. Em duas morfologias foi possível a identificação pontual dos seguintes elementos detectados nos pontos (1) e (2) das micrografias apresentadas na Figura 5: preponderantemente silício, alumínio e sódio e impurezas como potássio. As análises são consistentes com as fases identificadas nos difratogramas, indicando a presença de partículas com constituição de albita, mulita e quartzo.

Figura 3 - Análise de difração de raios X do RPP0 e do RPP1
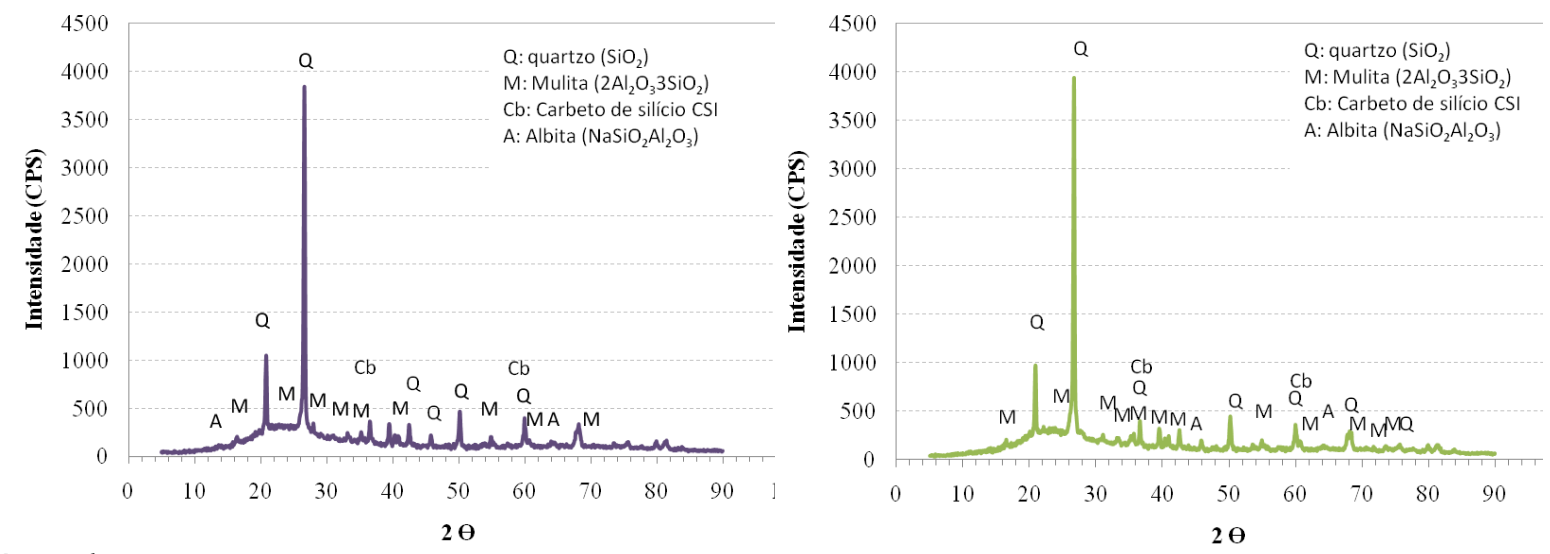

Legenda:

Q: quartzo $\left(\mathrm{SiO}_{2}\right)$;

M: mulita $\left(2 \mathrm{Al}_{2} \mathrm{O}_{3} \mathrm{SiO}_{2}\right)$;

Cb: carbeto de silício CSI; e

A: albita $\left(\mathrm{NaSiO}_{2} \mathrm{Al}_{2} \mathrm{O}_{3}\right)$. 
Figura 4 - Micrografias dos resíduos de polimento de porcelanato RPP0 e RPP1

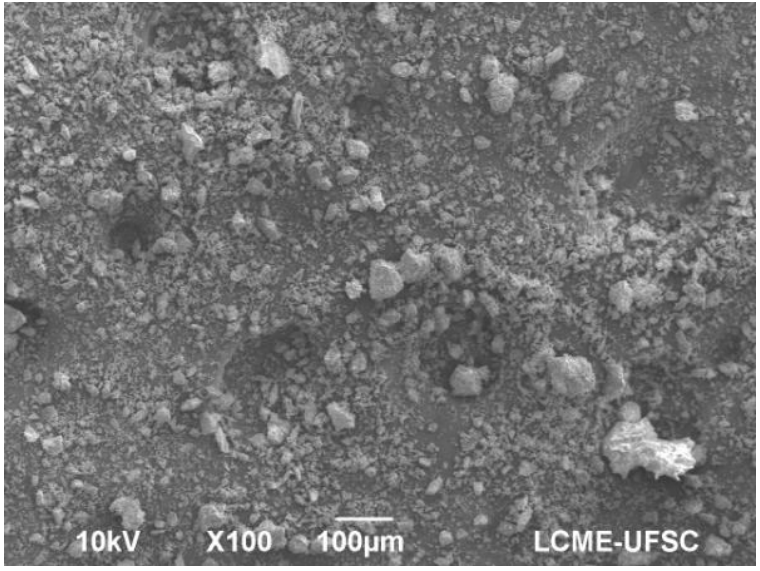

(a) RPP0

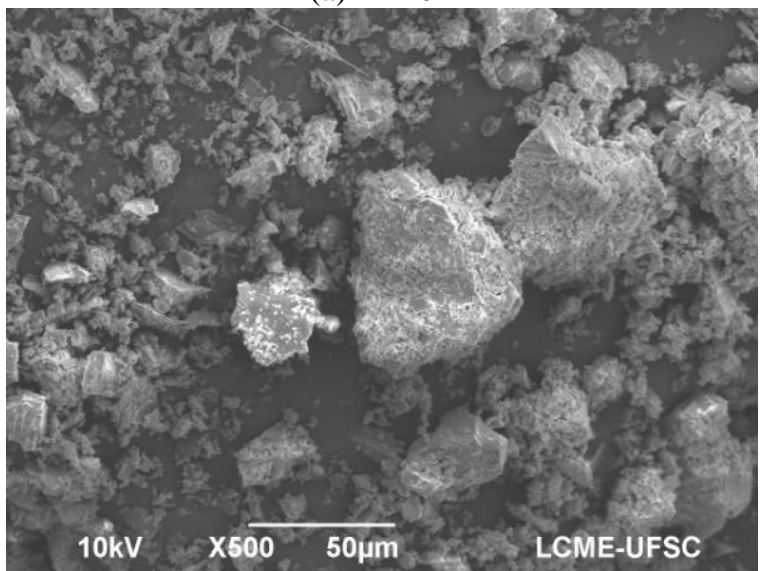

(b) RPP0

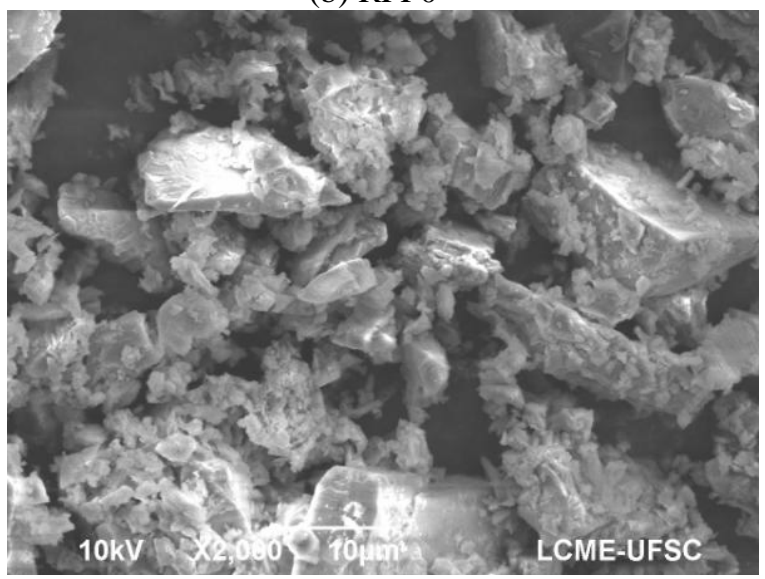

(c) RPP0

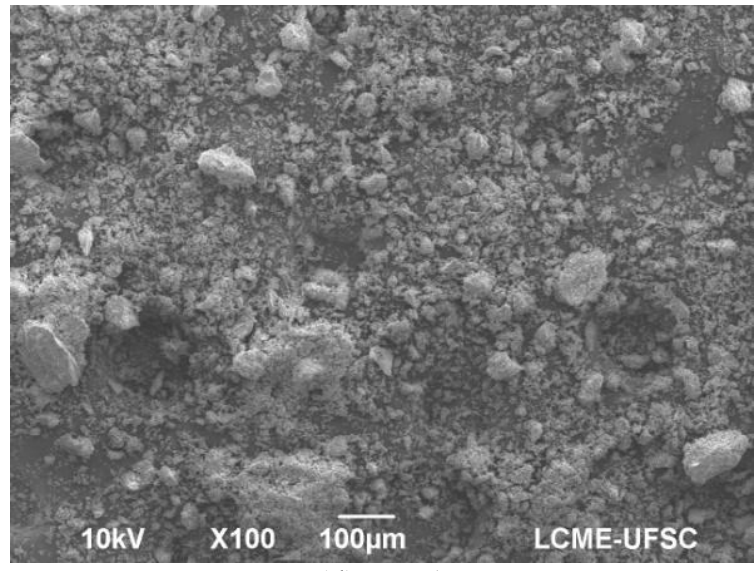

(d) RPP1

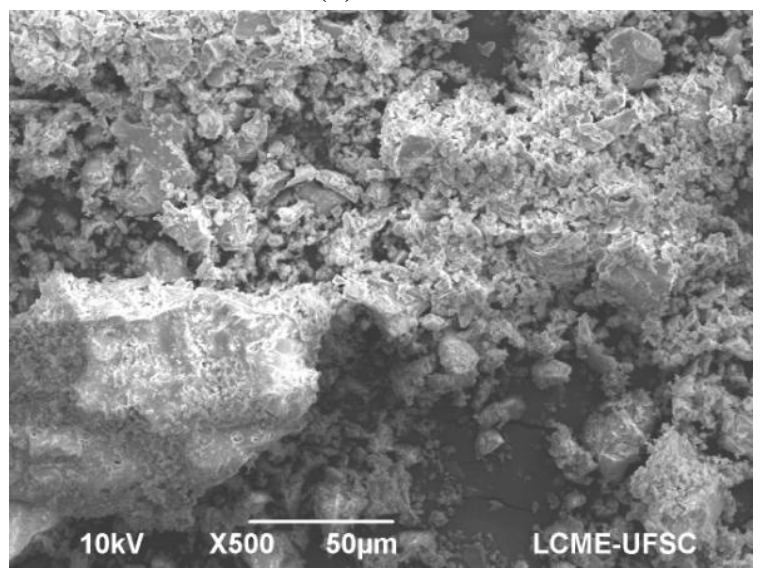

(e) RPP1

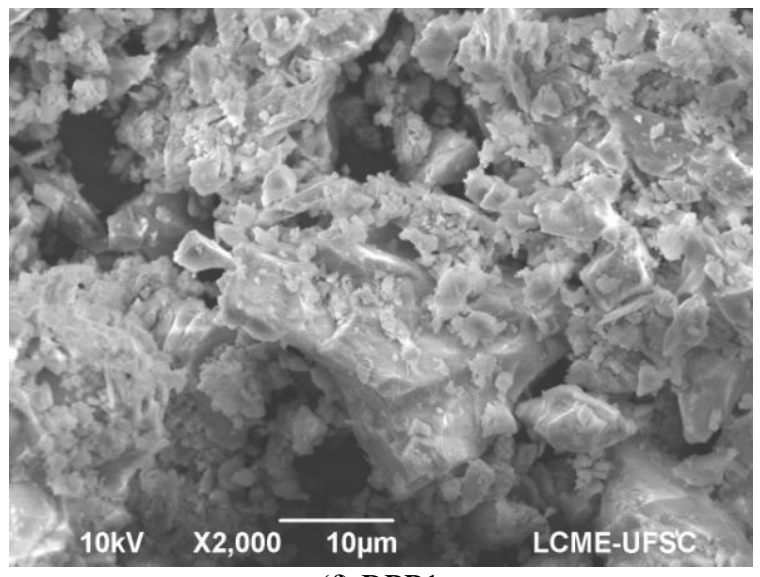

(f) RPP1 
Figura 5 - Micrografias dos resíduos de polimento de porcelanato RPPO e RPP1

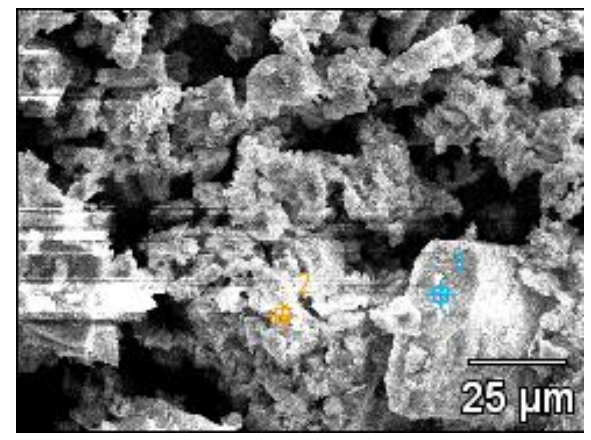

(a) RPP0

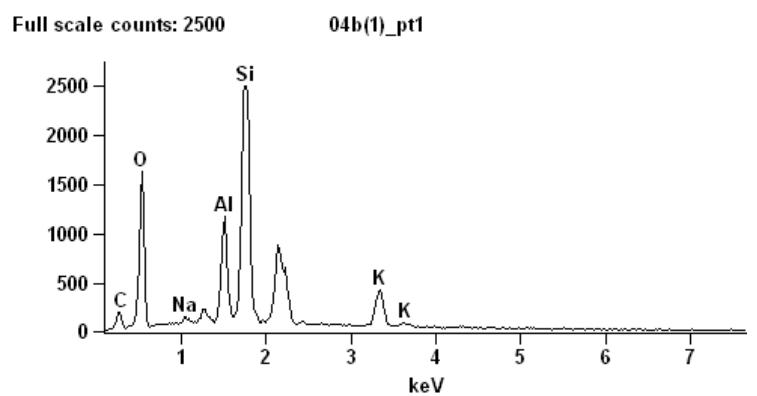

Full scale counts: $2500 \quad 04 \mathrm{~b}(1) \_p t 2$

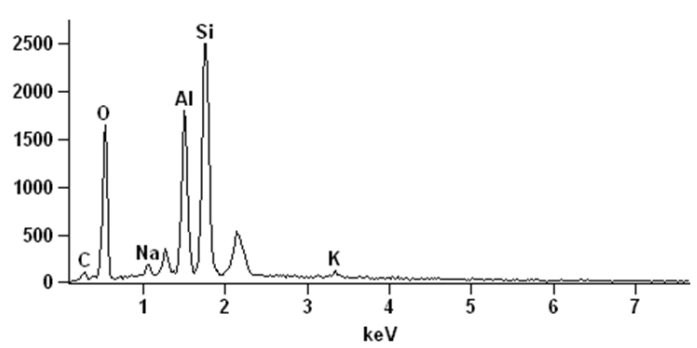

(c) RPP0

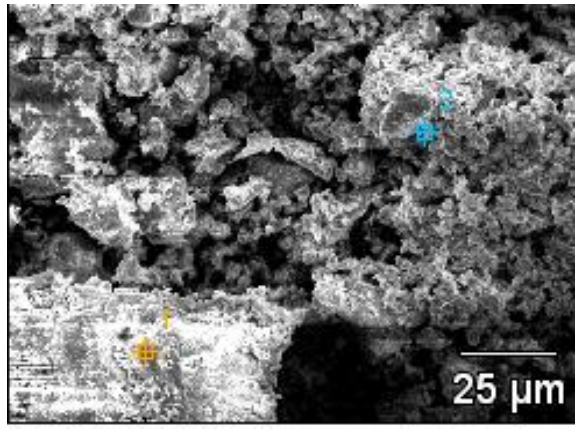

(b) RPP1

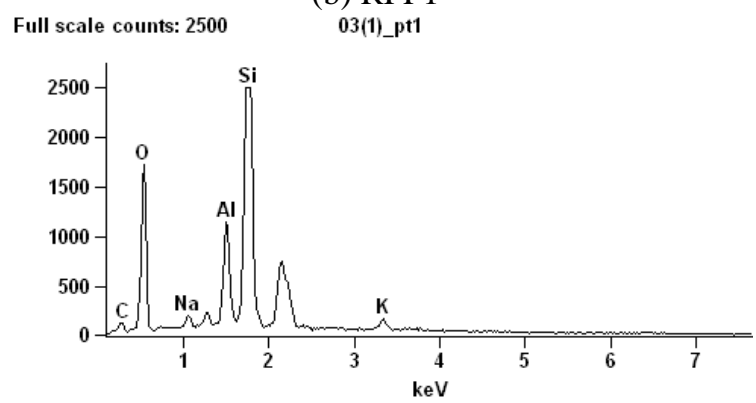

Full scale counts: $2500 \quad 03(1) \_p t 2$

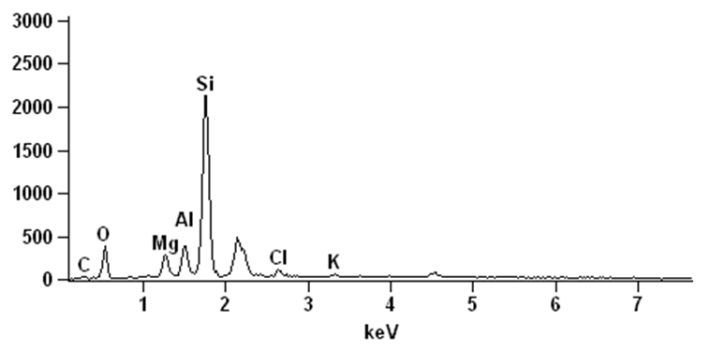

(d) RPP1

\section{Produção das argamassas autoadensáveis}

Para a produção das argamassas autoadensáveis (AAA), foi utilizado um traço de 1:3 (cimento:areia, em massa), com uma relação água/cimento constante de 0,85 (em massa) e com $50 \%$ de fíler calcário (em relação à massa de cimento Portland), baseado no traço utilizado por Martins et al. (2019). Os resíduos RPP0 e RPP1 foram adicionados em 10\%, 20\%, 30\% e 50\% em relação à massa de cimento Portland.

Os teores de aditivos SP e VMA (Tabela 5) foram ajustados para a argamassa confeccionada com o RPP0 em função dos valores obtidos de espalhamento (diâmetro maior ou igual a $220 \mathrm{~mm}$ ), parâmetro recomendado pela norma europeia para AAA (EUROPEAN..., 2001). As concentrações dos aditivos foram ajustadas para os diferentes teores de RPP0 analisados. Esses valores foram replicados para as argamassas com RPP1 com o propósito de avaliar o efeito da ASE e da granulometria.

Como os dois resíduos possuem a mesma massa específica $\left(2,31 \mathrm{~g} / \mathrm{cm}^{3}\right)$, a adição em volume nas argamassas foi a mesma. A quantidade utilizada de cada material por metro cúbico de argamassa está apresentada na Tabela 6. Nota-se que mesmo utilizando o RPP como adição, e não substituição, ao cimento Portland, como a maioria dos pesquisadores o faz, observa-se que o consumo de cimento Portland por metro cúbico reduz com o aumento da adição do resíduo. 
Tabela 5 - Quantidade de aditivos SP e VMA utilizados, em relação à massa de cimento Portland

\begin{tabular}{c|c|c|c|c|c}
\hline Aditivo & Referência & $\mathbf{1 0 \%}$ RPP & 20\% RPP & 30\% RPP & 50\% RPP \\
\hline SP (\%) & 0,70 & 0,90 & 0,90 & 1,10 & 1,35 \\
VMA (\%) & 0,70 & 0,70 & 0,70 & 0,70 & 0,70 \\
\hline
\end{tabular}

Tabela 6 - Consumo real dos componentes das AAA em quilograma por metro cúbico de argamassa no estado fresco

\begin{tabular}{|c|c|c|c|c|c|c|c|c|}
\hline \multicolumn{2}{|c|}{ Argamassas } & Cimento & Areia & Água & Fíler & RPP & VMA & SP \\
\hline \multicolumn{2}{|c|}{ Referência } & 373,34 & $1.120,04$ & 317,34 & 186,67 & $\mathbf{0 , 0 0}$ & 2,61 & 2,61 \\
\hline $10 \%$ & & 371,09 & $1.113,28$ & 315,42 & 185,55 & 37,11 & 2,60 & 3,33 \\
\hline $20 \%$ & RPPO & 362,22 & $1.086,67$ & 307,89 & 181,11 & 72,44 & 2,53 & 3,25 \\
\hline $30 \%$ & RPPO & 360,27 & $1.080,81$ & 306,23 & 180,13 & 108,08 & 2,52 & 3,96 \\
\hline $50 \%$ & & 358,00 & $1.074,00$ & 304,30 & 179,00 & 178,99 & 2,51 & 4,82 \\
\hline $10 \%$ & & 366,38 & $1.099,15$ & 311,52 & 183,19 & 36,64 & 2,56 & 3,29 \\
\hline $20 \%$ & PDD & 350,63 & $1.051,91$ & 298,04 & 175,32 & 70,13 & 2,45 & 3,15 \\
\hline $30 \%$ & RPPI & 342,05 & $1.026,16$ & 290,74 & 171,03 & 102,62 & 2,39 & 3,76 \\
\hline $50 \%$ & & 339,56 & $1.018,68$ & 288,62 & 169,78 & 169,78 & 2,38 & 4,58 \\
\hline
\end{tabular}

Foram estimados os parâmetros reológicos, de mobilidade e empacotamento das composições:

(a) área superficial volumétrica (ASV);

(b) área superficial específica (ASE);

(c) porosidade; distância de separação entre as partículas finas (IPS); e

(d) espessura da camada de pasta entre os agregados (MPT).

A distância de separação entre as IPS foi determinada pela Equação 1 (OLIVEIRA et al., 2000):

$I P S=\frac{2}{A S V} x\left[\frac{1}{V S}-\left(\frac{1}{1-P o f}\right)\right]$

Onde:

VSA é a área superficial volumétrica (produto da área superficial específica e a densidade real do pó);

Vs é a fração volumétrica de sólidos; e

Pof é a porosidade teórica do sistema, quando todas as partículas da matriz estão em contato na condição de máximo empacotamento, estimada segundo o método de Westman e Hugill (1930 ${ }^{1}$ apud OLIVEIRA et al., 2000).

Segundo Maciel et al. (2018), para a espessura da camada de pasta que afasta os MPT, pode-se utilizar a equação original de IPS, modificando os parâmetros VSAg (área superficial volumétrica da fração grossa), Pof $_{\mathrm{g}}$ (porosidade teórica da distribuição das partículas grossas, método de Westman e Hugill) e $\mathrm{VS}_{\mathrm{g}}$ (concentração volumétrica dos grossos), conforme apresenta a Equação 2.

$M P T=\frac{2}{V S A_{g}} x\left[\frac{1}{V s_{g}}-\left(\frac{1}{1-P o f_{g}}\right)\right]$

Eq. 2

O processo de mistura das argamassas foi realizado em argamassadeira planetária, com a seguinte sequência: mistura dos materiais secos por $60 \mathrm{~s}$, em seguida a adição de $50 \%$ da água e mistura por mais $60 \mathrm{~s}$, o restante da quantidade de água e mistura por $60 \mathrm{~s}$. Após o procedimento inicial, com a argamassadeira desligada, foi adicionado o aditivo dispersante (SP) eligou-se a argamassadeira por mais $60 \mathrm{~s}$. Por último, foi acrescentado $\mathrm{o}$ aditivo promotor de viscosidade e mistura por $120 \mathrm{~s}$.

\section{Ensaios no estado fresco e endurecido}

Foram determinadas as seguintes propriedades no estado fresco:

${ }^{1}$ WESTMAN, A. E. R.; HUGILL, H. R. The packing of particles. Journal of American Ceramic Society, v. 13, n. 10, p. 767-779, 1930. 
(a) segregação e exsudação (análise da aparência de borda);

(b) fluidez e trabalhabilidade através do ensaio de espalhamento na mesa, baseado no minicone, conforme a NBR 13276 (ABNT, 2016), porém sem aplicação de golpes; e

(c) densidade de massa e teor de ar incorporado de acordo com a NBR 13280 (ABNT, 2005a).

Já no estado endurecido, foram avaliadas: densidade de massa aparente, conforme a NBR 13280 (ABNT, 2005a); e resistência à compressão e resistência à tração na flexão, de acordo com a NBR 13279 (ABNT, 2005b) aos 28 dias. Os resultados foram avaliados de acordo com os parâmetros estabelecidos pela norma europeia (EUROPEAN..., 2001), que sugere para resistência à tração na flexão valores $\geq 5 \mathrm{MPa}$, e para resistência à compressão, valores $\geq 20 \mathrm{MPa}$. Foi utilizado o teste de Duncan para análise estatística dos resultados.

Após 48 h no molde, os corpos de prova ficaram 5 dias em ambiente com 95 $\pm 5 \%$ de umidade, e 21 dias em $65 \pm 5 \%$, com temperatura de $23 \pm 2{ }^{\circ} \mathrm{C}$, conforme preconiza a norma EN 13892-1 (BRITISH..., 2002).

A eficiência das argamassas com uso de RPP foi avaliada através do Índice de Intensidade de Ligante (IL) (DAMINELI, 2013). O valor é obtido através da relação entre o consumo de cimento Portland da argamassa em quilograma por metro cúbico e valor obtido de resistência à compressão no estado endurecido, em Megapascal (Equação 3). Esse valor permite uma comparação das diferentes argamassas avaliadas. Quanto maior seu valor, maior é a quantidade de cimento Portland para a mesma função,nesse caso resistência à compressão aos 28 dias e, portanto, menos ecoeficiente a mistura. Já o percentual de eficiência foi calculado com a Equação 4.

$I L=\frac{\text { Consumo de Cimento }\left(\mathrm{Kg} / \mathrm{m}^{3}\right)}{\text { Resist ência àCompress ão }(\mathrm{MPa})}$

$\%$ Eficiência $=\frac{\left(I L_{\text {refer ência }}-I L_{\text {argamassa ensaiada }}\right)}{I L_{\text {refer ência }}} \cdot 100$,

Eq. 4

onde:

IL é o índice de intensidade de ligante;

$\mathrm{IL}_{\text {referência }}$ é a intensidade de ligante da argamassa referência; e

$\mathrm{IL}_{\text {argamassaensaiada }}$ é a intensidade de ligante da argamassa com RPP.

\section{Resultados e discussões}

Os parâmetros reológicos calculados, de mobilidade e empacotamento das composições, encontram-se na Tabela 7. Ressalta-se que, para se calcular o valor de espessura da camada de pasta que afasta os agregados (MPT), não foi levado em consideração o teor de ar porque este é função da condição de mistura. Caso o teor de ar fosse o mesmo, a composição com RPP0 exigiria mais pasta para afastar os grãos, pois, segundo Romano et al. (2016), quando o teor de pasta for suficiente para exceder a porosidade do sistema e recobrir a superfície das partículas, pode-se esperar que o sistema flua.

Tabela 7 - Parâmetros de mobilidade e empacotamento de partículas sólidas das composições referência e com utilização de RPP0 e de RPP1

\begin{tabular}{c|c|c|c|c|c|c}
\hline Resíduo & Argamassas & $\begin{array}{c}\text { ASV } \\
\left(\mathbf{m}^{2} / \mathbf{c m}^{3}\right)\end{array}$ & $\begin{array}{c}\text { ASE } \\
\left(\mathbf{m}^{2} / \mathbf{g}\right)\end{array}$ & $\begin{array}{c}\text { Porosidade } \\
(\mathbf{\%})\end{array}$ & $\begin{array}{c}\text { IPS } \\
(\boldsymbol{\mu m})\end{array}$ & $\begin{array}{c}\text { MPT } \\
(\boldsymbol{\mu m})\end{array}$ \\
\hline- & Referência & $\mathbf{1 , 3 2}$ & $\mathbf{0 , 4 8}$ & $\mathbf{1 0 , 5 2}$ & $\mathbf{1 , 1 1 4}$ & $\mathbf{2 , 2 2 9}$ \\
\hline \multirow{3}{*}{ RPP0 } & $10 \%$ & 1,82 & 0,66 & 9,74 & 0,655 & 2,322 \\
& $20 \%$ & 2,29 & 0,83 & 8,99 & 0,464 & 2,413 \\
& $30 \%$ & 2,73 & 1,00 & 8,25 & 0,359 & 2,499 \\
& $50 \%$ & 3,54 & 1,31 & 6,76 & 0,248 & 2,675 \\
\hline \multirow{3}{*}{ RPP1 } & $10 \%$ & 2,03 & 0,74 & 9,71 & 0,559 & 2,326 \\
& $20 \%$ & 2,71 & 0,99 & 8,92 & 0,372 & 2,42 \\
& $30 \%$ & 3,35 & 1,23 & 8,15 & 0,278 & 2,51 \\
& $50 \%$ & 4,53 & 1,67 & 6,58 & 0,185 & 2,694 \\
\hline
\end{tabular}

394 Betioli, A. M.; Fortunato, M.; Martins, B.-H. R.; Casali, J. M.; Rocha, J. C.; Collodetti, G. 
Nota-se que as composições com adição de resíduo de polimento de porcelanato RPP1 apresentam valores maiores de ASV e ASE, e menor distância de separação entre as IPS devido à maior área superficial específica do grão e à granulometria mais fina. Essa diferença pode impactar, por exemplo, na demanda de água ou aditivo, uma vez que o aumento na área específica dos sistemas, por exemplo, pode resultar em aumento da demanda de água para o amassamento e a manutenção da consistência desejada. A porosidade de empacotamento teórica indica o volume de vazios microestruturais resultantes da combinação das matérias-primas. Observa-se que a adição do RPP1 reduz a porosidade do sistema.

Os valores obtidos de diâmetro de espalhamento das argamassas autoadensáveis são apresentados na Tabela 8 , juntamente com a densidade de massa. Os registros fotográficos, para análise de uniformidade de borda, estão apresentados na Tabela 9.

É possível notar que, exceto a argamassa com 50\% de RPP1 (RPP de maior área superficial específica), todas as argamassas analisadas obtiveram valores de espalhamento dentro do exigido pela norma (diâmetro $\geq 220 \mathrm{~mm}$ ). Isso ocorreu em virtude do ajuste na quantidade de aditivo SP (Tabela 5) de acordo com a quantidade de RPP0 utilizada na mistura. O aumento no teor de aditivo SP foi necessário porque, quanto maior a quantidade de fino na mistura, maior a viscosidade da argamassa e, com isso, menor sua fluidez (Figura 6). O uso de fino de grande área superficial específica resulta em maior adsorção de água, reduzindo a fluidez da mistura (CARVALHO, 2015), além de a distribuição granulométrica do RPP ser mais fina que a do cimento Portland (PELISSER; STEINER; BERNARDIN, 2012). Nesse caso, a elevada área superficial específica dos resíduos (cerca de 10 vezes maior que do cimento Portland, Tabelas 1 e 2) reduziu a água livre da mistura, tornando a argamassa mais viscosa, fato também observado por Matos et al. (2018) em concreto autoadensável.

Todas as argamassas apresentaram bordas uniformes sem vestígios de segregação ou exsudação, mas manter o teor de aditivo constante mostrou que o RPP0, por ter menor área superficial específica e partículas mais grossas, necessita de menor teor de aditivo. Esse efeito pode ser verificado nas imagens da Tabela 9, em que as AAA com RPP0 apresentam espalhamento mais uniforme e com melhor aparência de borda que as com RPP1.

Tabela 8 - Valores de espalhamento em ensaio de minicone e densidade de massa no estado fresco das argamassas referência e com utilização de RPPO e de RPP1

\begin{tabular}{c|c|c|c|c|c|c|c|c|c}
\hline \multirow{2}{*}{ Argamassas } & \multirow{2}{*}{ REF } & \multicolumn{2}{|c|}{$\mathbf{1 0 \%}$} & \multicolumn{2}{c|}{ 20\% RPP } & \multicolumn{2}{c|}{ 30\% RPP } & \multicolumn{2}{c}{ 50\% RPP } \\
\cline { 3 - 9 } & & RPP0 & RPP1 & RPP0 & RPP1 & RPP0 & RPP1 & RPP0 & RPP1 \\
\hline Minicone $(\mathrm{mm})$ & 279 & 327,5 & 322,5 & 302,5 & 237,0 & 325,0 & 286,5 & 360,0 & 207,5 \\
$\begin{array}{c}\text { Densidade de } \\
\text { massa }\left(\mathrm{g} / \mathrm{cm}^{3}\right)\end{array}$ & 2,00 & 2,02 & 2,02 & 2,02 & 1,95 & 2,04 & 1,94 & 2,10 & 1,99 \\
\hline
\end{tabular}

Tabela 9 - Imagens dos espalhamentos das argamassas autoadensáveis referência e com utilização de RPP0 e de RPP1

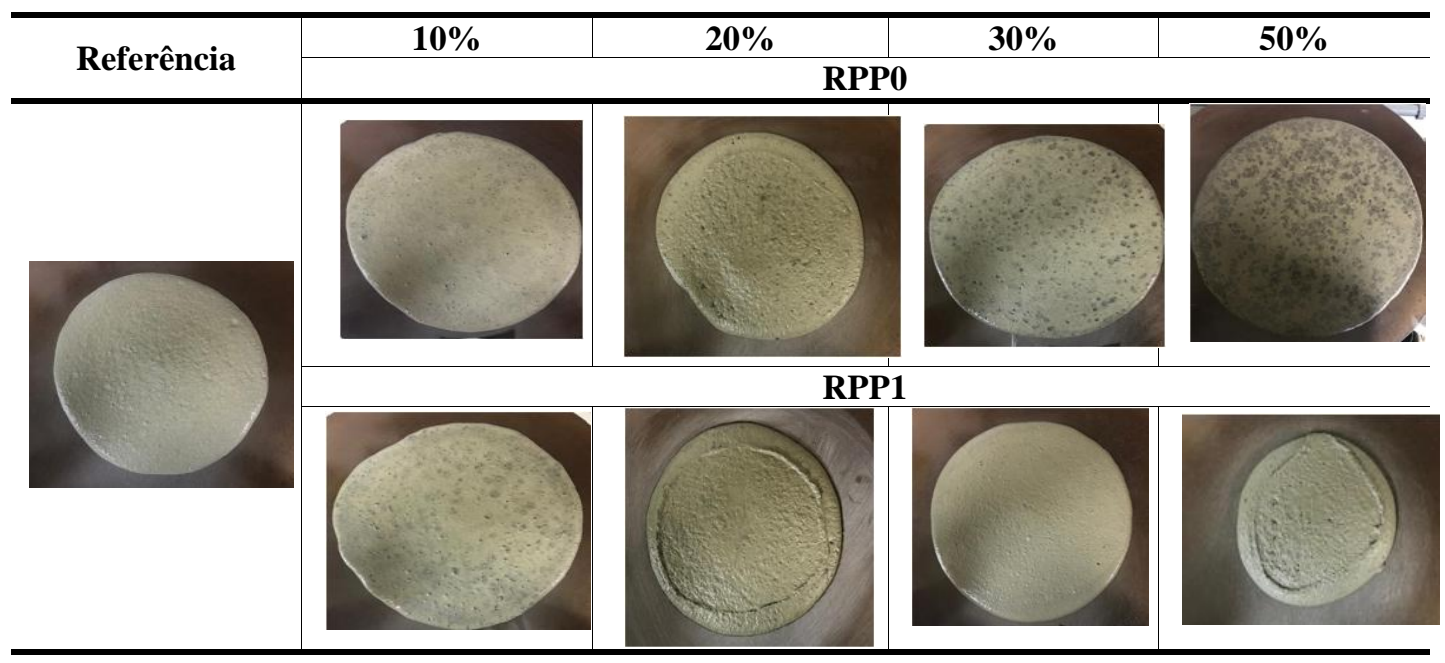


Comparando o efeito do RPP, nota-se que o RPP1, por ser mais fino e com maior área superficial específica, em relação ao RPP0, exigiria teor maior de aditivo para a mesma fluidez, fato observado por Matos et al. (2018), em que, ao substituir cimento Portland por RPP, foi necessário aumento no teor de aditivo para manter a fluidez. Assim, para este estudo, em que foi fixado o teor de aditivo SP para o mesmo teor de adição de RPP, a argamassa com RPP1 apresentou menor fluidez (Tabela 8).

A Figura 6 apresenta o teor de ar incorporado nas argamassas autoadensáveis com diferentes porcentagens de adição de RPP0 e de RPP1, e o teor de aditivo SP utilizado. Segundo Mattana e Costa (2010), o efeito do aditivo dispersante pode ocasionar maior incorporação de ar. Observa-se aumento no teor de ar incorporado com aumento do aditivo SP, até um limite de teor de adição, para RPP0 até $20 \%$ e para RPP1 até 30\%. Após esse limite, houve diminuição no teor de ar incorporado.

Observa-se ainda na Figura 6 que o menor teor de ar incorporado nas argamassas com RPP0 pode ser explicado pela menor viscosidade da pasta, que reduz a estabilidade das bolhas de ar, acelerando a coalescência e a eliminação delas (ROMANO et al., 2012). O contrário foi observado com a adição de RPP1 (Figura 6), em que a menor fluidez e a maior coesão da argamassa mantiveram estável o ar incorporado aprisionado durante a mistura.

Esse resultado já demonstra que a variabilidade da granulometria e da área superficial específica dos RPP produzidos pela mesma fábrica podem alterar o consumo de aditivo superplastificante para determinada fluidez e, ainda mais importante, influenciar no teor de ar incorporado, o qual poderá afetará o desempenho no estado endurecido, conforme apresentando nas Figuras 7 e 9.

Observa-se na Figura 7 que os valores de resistência à compressão tiveram valores maiores que o mínimo exigido pela norma (20 $\mathrm{MPa}$ - indicado com uma linha cheia na Figura 7) para todas as argamassas ensaiadas. Nota-se ainda que a adição do RPP0 aumentou a resistência à compressão com o aumento no teor de RPP adicionado. Já a adição de $20 \%$ e $30 \%$ de RPP1não alterou a resistência à compressão devido ao teor de ar incorporado e, somente com a utilização 50\% deste resíduo, observou-se o aumento de $40 \%$ da resistência em relação à referência.

Figura 6 - Teor de incorporado e teor de aditivo SP nas argamassas referência e com utilização de RPP0 e de RPP1

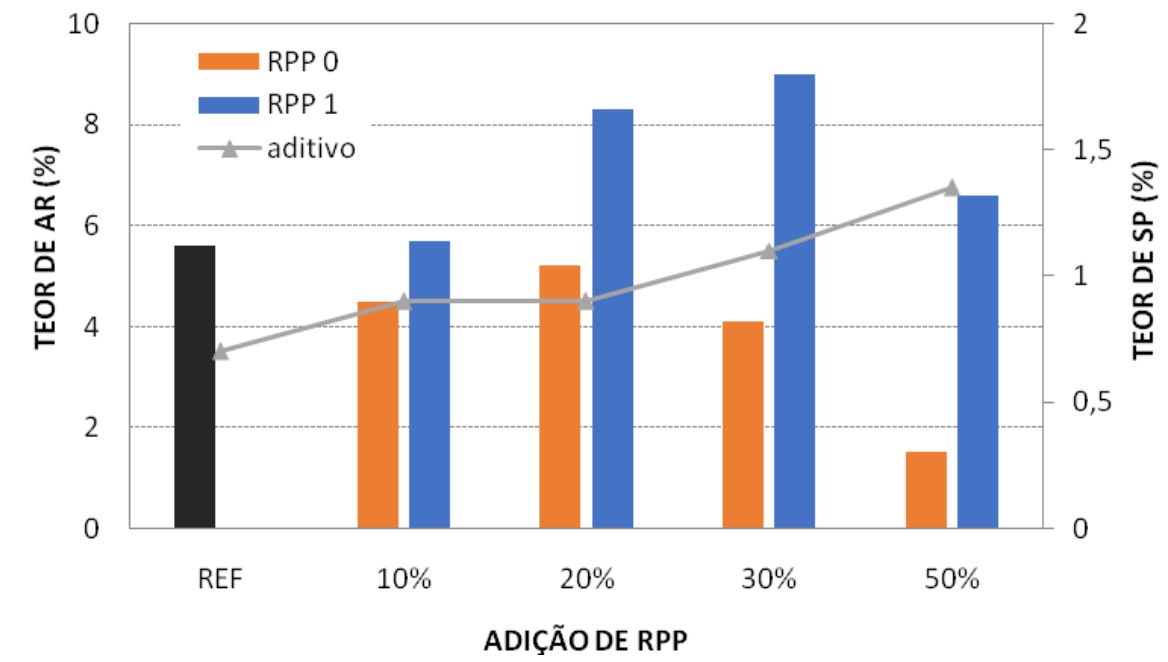

396 Betioli, A. M.; Fortunato, M.; Martins, B.-H. R.; Casali, J. M.; Rocha, J. C.; Collodetti, G. 
Figura 7 - Resistência à compressão das argamassas referência e com utilização de RPP0 e de RPP1

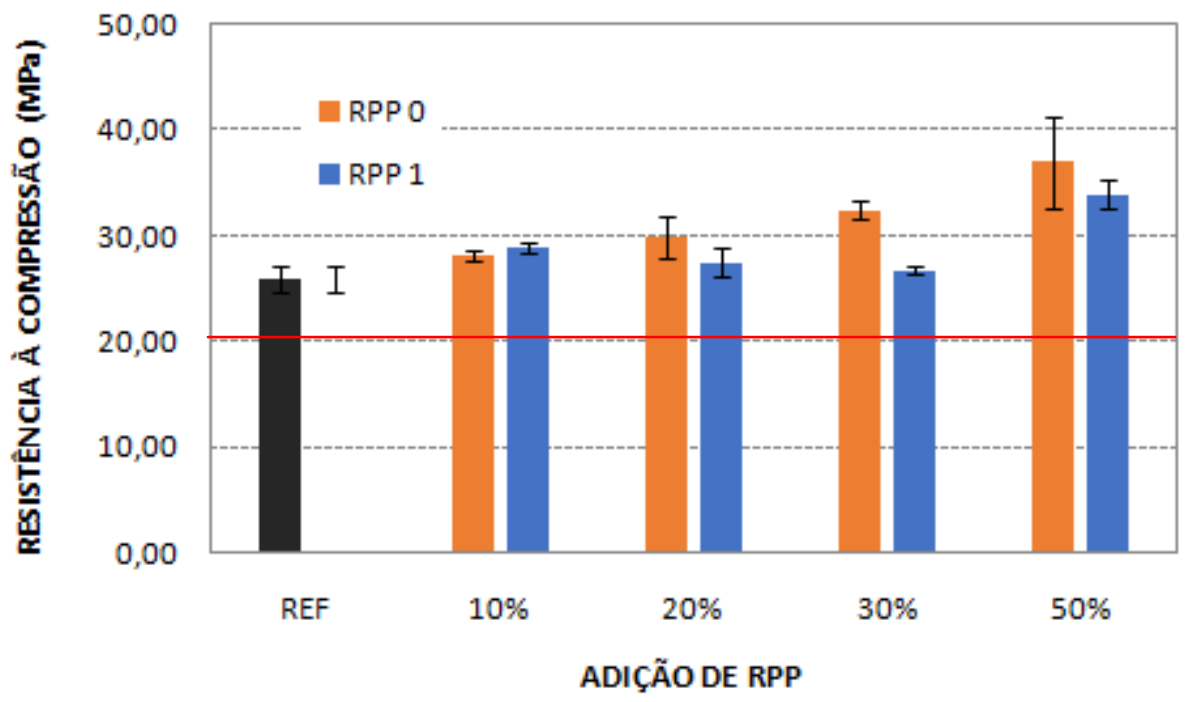

O aumento da resistência à compressão com o uso do RPP também foi observado por Pelisser, Steiner e Bernardin (2012). Segundo os autores, a calorimetria isotérmica apontou aumento do calor liberado com o acréscimo no teor de RPP, indicando potencialização na cinética de hidratação pela disponibilidade de pontos de nucleação para formação dos géis de C-S-H. Ainda, os autores atribuíram esse aumento à atividade pozolânica do resíduo, uma vez que fizeram uma avaliação ao longo do tempo (até 56 dias) e ao efeito fíler, devido à redução na porosidade e na permeabilidade da matriz. A atividade pozolânica também foi comprovada por Steiner (2014), Jacoby e Pelisser (2015) e Matos et al. (2018).

A análise nesta pesquisa foi realizada aos 28 dias. Assim, possivelmente, esse aumento pode ser atribuído principalmente à melhora no empacotamento granulométrico da mistura diminuindo o volume de vazios, conforme citado por Fiorentin (2011), como mostra a redução da porosidade do esqueleto na Tabela 7para os dois resíduos de RPP utilizados.

Sabe-se que o principal fator que governa a resistência mecânica de materiais à base de cimento é a relação água/cimento. Entretanto, segundo Matos (2019), o emprego de adições minerais inertes (amplamente utilizadas em concretos autoadensáveis) pode melhorar o empacotamento do material, reduzindo a porosidade e, consequentemente, aumentando a resistência mecânica dele. Uysal e Yilmaz (2011) reiteram que o melhor empacotamento promovido pelas adições forma matrizes mais densas, além de proporcionar melhor dispersão dos grãos de cimento e formação de pontos de nucleação para os géis de C-S-H.

Com relação aos diferentes RPP avaliados, como a relação água/cimento foi mantida constante, o maior teor de ar incorporado aprisionado nas argamassas com RPP1 pode ter influenciado para um menor ganho de resistência, pois, segundo Torres, Romano e Pileggi (2017), a porosidade pode representar defeitos críticos que diminuem a resistência mecânica, como pode ser visto nos valores de densidade de massa no estado endurecido.

Apesar da maior área superficial específica do RPP1 e da menor porosidade teórica do sistema, (Tabela 7), o teor de ar nas argamassas autoadensáveis com esse resíduo foi maior (Figura 6), consequentemente menor densidade de massa aparente (Figura 8), possivelmente influenciando para um menor ganho de resistência à compressão (Tabela 10) em relação às argamassas autoadensáveis com adição de RPP0, conforme já mencionado. 
Figura 8 - Densidade de massa no estado endurecido das argamassas referência e com utilização de RPP0 e de RPP1

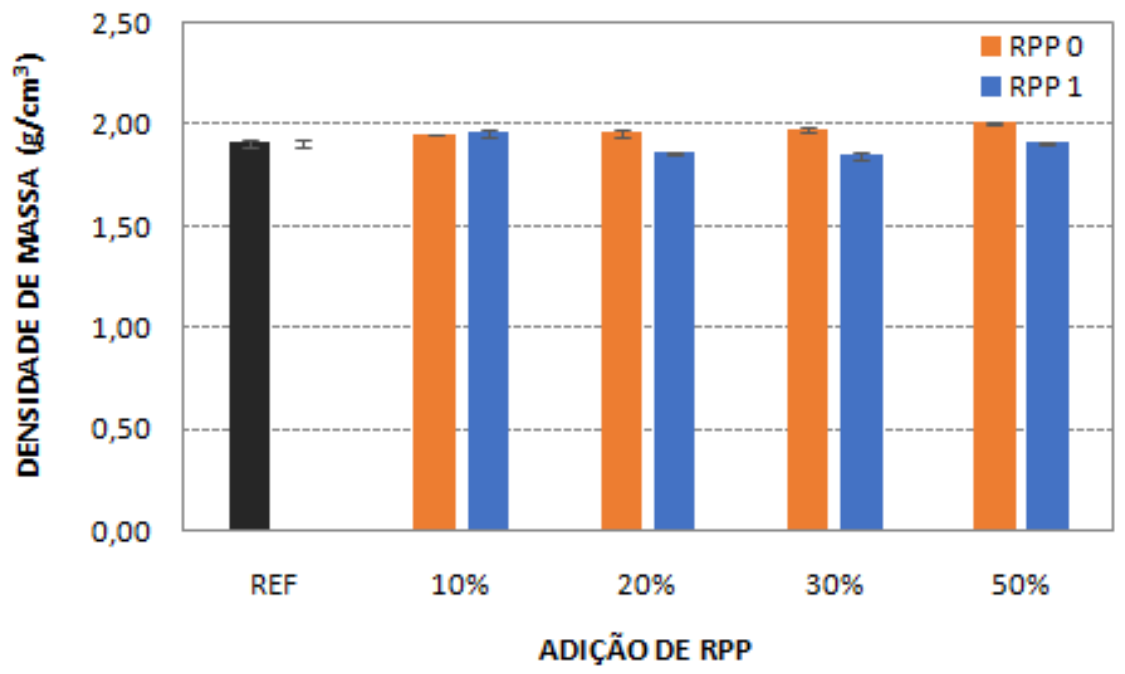

Tabela 10 - Resistência à compressão e ganho em relação à referência das argamassas

\begin{tabular}{|c|c|c|c|}
\hline \multicolumn{2}{|c|}{ REF } & \multirow{2}{*}{$\begin{array}{c}\begin{array}{c}\text { Resistência à } \\
\text { compressão (MPa) }\end{array} \\
25,8\end{array}$} & \multirow[t]{2}{*}{$\begin{array}{c}\text { Ganho \% na } \\
\text { resistência }\end{array}$} \\
\hline \multirow{3}{*}{$10 \%$} & & & \\
\hline & RPP0 & 28,1 & $8,9 \%$ \\
\hline & RPP1 & 28,9 & $11,8 \%$ \\
\hline \multirow{2}{*}{$20 \%$} & RPP0 & 29,9 & $15,7 \%$ \\
\hline & RPP1 & 27,5 & $6,3 \%$ \\
\hline \multirow{2}{*}{$30 \%$} & RPP0 & 32,4 & $25,6 \%$ \\
\hline & RPP1 & 26,8 & $3,6 \%$ \\
\hline \multirow{2}{*}{$50 \%$} & RPP0 & 38,6 & $49,6 \%$ \\
\hline & RPP1 & 33,9 & $31,4 \%$ \\
\hline
\end{tabular}

Os valores de resistência à tração na flexão apresentaram grande variabilidade (Figura 9), e somente foi possível observar aumento expressivo com a utilização de 50\% de RPP para os dois tipos avaliados; novamente, o efeito do teor de ar foi maior para as argamassas com RPP1.

Observa-se que os valores de resistência à tração na flexão, assim como os valores de resistência à compressão, tiveram valores maiores que o mínimo exigido pela norma (5 MPa) para todas as argamassas ensaiadas.

Nas Tabelas 11 e 12 são apresentados os resultados do índice de eficiência para as argamassas estudadas. Como se pode observar, conforme aumenta a utilização de RPP, o IL diminui e a eficiência da argamassa aumenta, possibilitando, assim, redução do consumo de cimento Portland. Esse comportamento foi mais evidente para o RPP0, apesar de menor área específica e granulometria mais grossa, pois o uso deste resultou em ganhos maiores de resistência, conforme comentado anteriormente e apresentado na Tabela 10.

Assim, foi comprovada melhora nas propriedades do estado endurecido de argamassas autoadensáveis utilizando RPP, sendo verificado um índice de eficiência de 35,89\% para o uso de 50\% do RPP0 (Tabela 11), possibilitando, dessa forma, redução ainda maior do consumo de cimento Portland por metro cúbico para uma mesma resistência.

398 Betioli, A. M.; Fortunato, M.; Martins, B.-H. R.; Casali, J. M.; Rocha, J. C.; Collodetti, G. 
Figura 9 - Resistência à tração na flexão das argamassas referência e com utilização de RPP0 e de RPP1

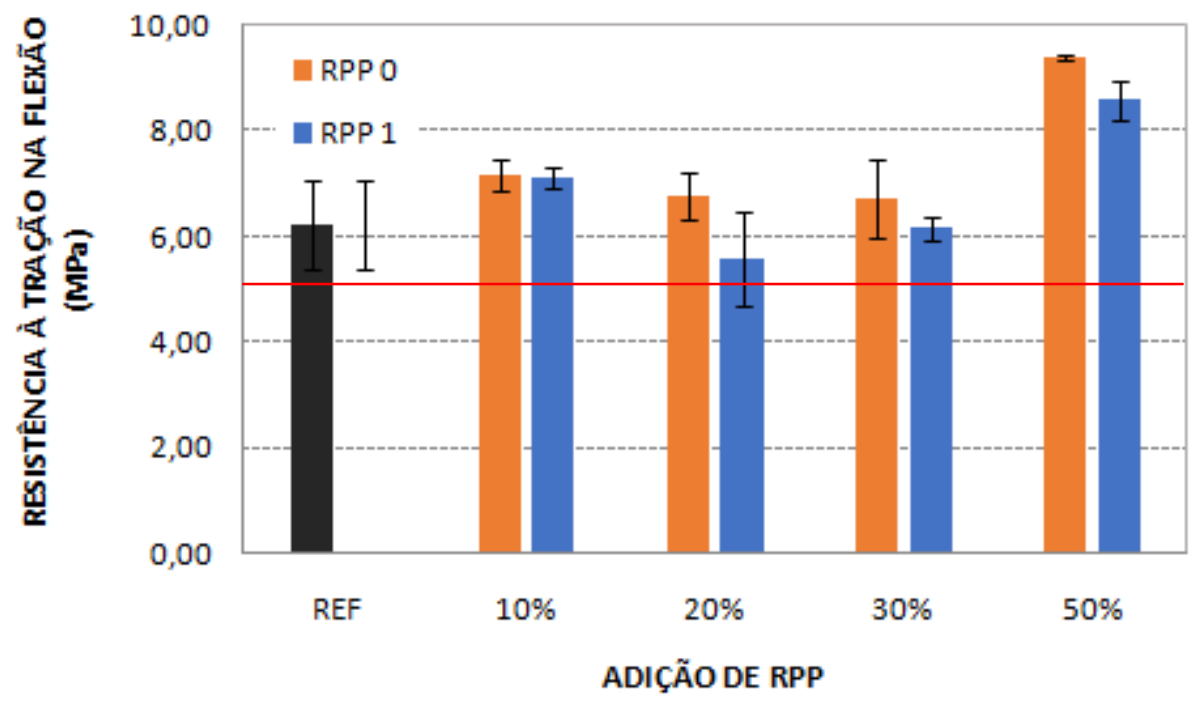

Tabela 11 - Resultados do índice de eficiência de cada argamassa estudada com RPPO

\begin{tabular}{l|c|c|c|c|c}
\hline & REF & 10\% RPP0 & 20\%RPP0 & 30\%RPP0 & 50\%RPP0 \\
\hline IL $\left(\mathrm{kg} / \mathrm{m}^{3} \cdot \mathrm{MPa}^{-1}\right)$ & 14,47 & 13,20 & 12,13 & 11,11 & 9,27 \\
\% Eficiência & $0,00 \%$ & $8,77 \%$ & $16,16 \%$ & $23,20 \%$ & $35,89 \%$ \\
Redução de cimento $\left(\mathrm{kg} / \mathrm{m}^{3}\right)$ & 0,00 & 2,25 & 11,12 & 13,08 & 15,35 \\
\hline
\end{tabular}

Tabela 12 - Resultados do índice de eficiência de cada argamassa estudada com RPP1

\begin{tabular}{l|c|c|c|c|c}
\hline & REF & 10\%RPP1 & 20\%RPP1 & 30\%RPP1 & 50\%RPP1 \\
\hline $\mathrm{IL}\left(\mathrm{kg} / \mathrm{m}^{3} \cdot \mathrm{MPa}^{-1}\right)$ & 14,47 & 12,70 & 12,78 & 12,79 & 10,01 \\
$\%$ Eficiência & $0,00 \%$ & $12,24 \%$ & $11,69 \%$ & $11,60 \%$ & $30,77 \%$ \\
Redução de cimento $\left(\mathrm{kg} / \mathrm{m}^{3}\right)$ & 0,00 & 6,97 & 22,71 & 31,29 & 33,79 \\
\hline
\end{tabular}

\section{Conclusão}

O intuito desta pesquisa foi avaliar o efeito da área superficial específica e da granulometria de resíduos de polimento de porcelanato na produção de argamassas autoadensáveis. As amostras, diferentes resíduos de RPP, mostraram que, apesar da composição química semelhante, as diferenças na composição granulométrica e na área superficial específica alteraram o desempenho das propriedades da argamassa autoadensável no estado fresco e endurecido.

Independentemente dos RPP utilizados, os resultados foram satisfatórios quando adicionados às argamassas autoadensáveis. Apesar da necessidade de ajuste na quantidade de aditivo superplastificante, conforme o aumento na adição do RPP, as argamassas apresentaram aumento ou não influenciaram nas resistências, e uma resultou em redução do consumo de cimento Portland por metro cúbico. Esses resultados podem ser explicados pelo efeito fíler da adição do fino, resultando em melhora no empacotamento do sistema.

Apesar de terem sido mantidos constantes a relação água/cimento e os teores de aditivos, ajustados para as argamassas com RPP0, a adição do resíduo RPP0 (menor área superficial específica e partículas mais grossas) resultou em menor teor de ar incorporado, e o aumento de resistência ocorreu já a partir de $10 \%$ de adição. Já as com o RPP1 (área superficial específica maior e partículas mais finas), a resistência à compressão aumentou com adições acima de 30\%. Esperavam-se resistências maiores com a adição do RPP1, pois a porosidade teórica desta composição é menor, o que resultaria em melhor empacotamento, mas isso não ocorreu possivelmente devido à maior viscosidade e coesão da argamassa, que acabou por estabilizar o ar na mistura, apresentando maior teor de incorporação de ar.

Assim, independentemente do teor e do tipo de RPP utilizados, uma vez que a composição química é semelhante e somente há diferença da composição granulométrica e da área superficial específica dos grãos 
de RPP, os resultados foram satisfatórios quando o resíduo foi adicionado às argamassas autoadensáveis. Portanto, o uso desses resíduos é viável como finos em argamassas autoadensáveis, o que permite o uso de um resíduo resultado de um processo de produção.

\section{Referências}

AMERICAN SOCIETY FOR TESTING AND MATERIALS. C618-05: standard specification for coal flyash and rawor calcined natural pozzolan for use in concrete. Philadelphia, 2012.

ANDREOLA, F. et al. New blended cement from polishing and glazing ceramic sludge. International Journal of Applied Ceramic Technology, v. 7, n. 4, p. 546-555, 2010.

ASSOCIAÇÃO BRASILEIRA DE NORMAS TÉCNICAS. NBR 10004: resíduos sólidos: classificação. Rio de Janeiro, 2004.

ASSOCIAÇÃO BRASILEIRA DE NORMAS TÉCNICAS. NBR 12653: materiais pozolânicos: requisitos. Rio de Janeiro, 2014. Versão corrigida: 2015.

ASSOCIAÇÃO BRASILEIRA DE NORMAS TÉCNICAS. NBR 13276: argamassa para assentamento e revestimento de paredes e tetos: determinação do índice de consistência. Rio de Janeiro, 2016.

ASSOCIAÇÃO BRASILEIRA DE NORMAS TÉCNICAS. NBR 13279: argamassa para assentamento e revestimento de paredes e tetos: determinação da resistência à tração na flexão e à compressão. Rio de Janeiro, 2005b.

ASSOCIAÇÃO BRASILEIRA DE NORMAS TÉCNICAS. NBR 13280: argamassa para assentamento e revestimento de paredes e tetos: determinação da densidade de massa aparente no estado endurecido. Rio de Janeiro, 2005a.

ASSOCIAÇÃO BRASILEIRA DE NORMAS TÉCNICAS. NBR 16605: cimento Portland e outros materiais em pó: determinação da massa específica. Rio de Janeiro, 2017.

ASSOCIAÇÃO BRASILEIRA DE NORMAS TÉCNICAS. NBR NM 248: agregados: determinação da composição granulométrica. Rio de Janeiro, 2003.

ASSOCIAÇÃO BRASILEIRA DE NORMAS TÉCNICAS. NBR NM 52: agregado miúdo: determinação de massa específica e massa específica aparente. Rio de Janeiro, 2009.

ASSOCIAÇÃO NACIONAL DOS FABRICANTES DE CERÂMICA PARA REVESTIMENTOS, LOUÇAS SANITÁRIAS E CONGÊNERES. Números do setor. Disponível em:

https://www.anfacer.org.br/. Acesso em: 20 set. 2019.

BERNARDIN, A. M. et al. Reaproveitamento de resíduos de polimento e de esmaltação para obtenção de cerâmica celular. Cerâmica Industrial, v. 11, p. 41-34, 2006.

BRITISH-ADOPTED EUROPEAN STANDARD. BS EN 13892-1: method of test for screed materials: sampling, making and curing specimens for test. London, 2002.

CARVALHO, H. D. S. Análise de retração por secagem em argamassas autonivelantes utilizando adições minerais como substitutos parciais do cimento Portland. Florianópolis, 2015. 138 f. Dissertação (Mestrado em Engenharia Civil) - Curso de Engenharia Civil, Universidade Federal de Santa Catarina, Florianópolis, 2015.

DAL MOLIN, D. C. C. Adições minerais. In: ISAIA, G. C. Concreto: ciência e tecnologia. São Paulo: Ibracon, 2011.

DAMINELI, B. L. Conceitos para formulação de concretos com baixo consumo de ligantes: controle reológico, empacotamento e dispersão de partículas. 2013. Tese (Doutorado em Engenharia de Construção Civil e Urbana) - Escola Politécnica, Universidade de São Paulo, São Paulo, 2013.

EUROPEAN FEDERATION FOR SPECIALIST CONSTRUCTION CHEMICALS AND CONCRETE SYSTEMS. Specification for synthetic resin and polymer-modified cementitious floorings as wearing surfaces for industrial and commercial use. London, 2001.

FIORENTIN, T. R. Influência do aditivo modificador de viscosidade e do fíler calcário no comportamento de pastas e argamassas de concreto autoadensável. Pato Branco, 2011. 68 f. Trabalho de Conclusão de Curso (Bacharelado em Engenharia Civil) - Universidade Tecnológica Federal do Paraná, Pato Branco, 2011. 
JACOBY, P. C.; PELISSER, F. Pozzolanic effect of porcelain polishing residue in Portland cement. Journal of Cleaner Production, v. 100, p. 84- 88, 2015.

KUMMER, L. et al. Reutilização dos resíduos de polimento de porcelanato e feldspato na fabricação de novos produtos cerâmicos. Cerâmica Industrial, v. 12, n. 3, p. 34-38, 2007.

MACIEL, M. H. et al. Efeito da variação do consumo de cimento em argamassas de revestimento produzidas com base nos conceitos de mobilidade e empacotamento de partículas. Ambiente Construído, Porto Alegre, v. 18, n. 1, p. 245-259, jan./mar. 2018.

MARTINS, B. H. R. et al. Influência da adição de diferentes finos em argamassa autoadensável. In: CONGRESSO BRASILEIRO DE CONCRETO, 61., Fortaleza, 2019. Anais [...] Fortaleza, 2019.

MARTINS, E. J. Procedimento para dosagem de pastas para argamassa autonivelante. Curitiba, 2009. Dissertação (Mestrado em Engenharia Civil) - Escola de Engenharia, Universidade Federal do Paraná, Curitiba, 2009.

MATOS, P. R. Estudo do uso de resíduo de polimento e porcelanato em concreto autoadensável. Florianópolis, 2019. Tese (Doutorado em Engenharia Civil) - Escola de Engenharia, Universidade Federal de Santa Catarina. Florianópolis, 2019.

MATOS, P. R. et al. Rheological behavior of Portland cement pastes and self-compacting concretes containing porcelain polishing residue. Construction and Building Materials, v. 175, p. 508-518, 2018.

MATTANA, A.; COSTA, M. Estudo da influência de aditivo dispersante no comportamento reológico de argamassas de revestimento, In: CONGRESSO PORTUGUÊS DE ARGAMASSAS DE CONSTRUÇÃO, 3., Lisboa, 2010. Anais [...] Lisboa, 2010.

NAKAKURA, E. H.; BUCHER, H. R. E. Pisos autonivelantes: propriedades e instalações. In: SIMPÓSIO BRASILEIRO DE TECNOLOGIA DAS ARGAMASSAS, 2., Salvador, 1997. Anais [...] Salvador, 1997.

OLIVEIRA, I. R. et al. Dispersão e empacotamento de partículas. São Paulo: Fazendo Arte, 2000.

PELISSER, F.; STEINER, L. R.; BERNARDIN, A. N. Recycling of porcelain tile polishing residue in Portland cement: hydration efficiency. Environmental Science \& Technology, v. 46, n. 4, p. 2368-2374, 2012.

ROMANO, R. C. O. et al. Viscosidade cinemática de pastas cimentícias com incorporadores de ar avaliadas em diferentes temperaturas. Cerâmica, v. 58, p. 58-65, 2012.

ROMANO, R. C. O. et al. Avaliação do estado endurecido de argamassas de revestimento em função da variação do consumo de cimento. In: SIMPÓSIO DE ARGAMASSAS E SOLUÇÕES TÉRMICAS DE REVESTIMENTO, 2., Coimbra, 2016. Anais [...] Coimbra, 2016.

SILVA, G. J. B. Estudo do comportamento do concreto de cimento Portland produzido com a adição do resíduo de polimento do porcelanato. Belo Horizonte, 2005. Dissertação (Engenharia Metalúrgica e de Minas) - Escola de Engenharia, Universidade Federal de Minas Gerais, Belo Horizonte, 2005.

SOUZA, P. A. B. F. Estudo do comportamento plástico, mecânico, microestrutural e térmico do concreto produzido com o resíduo do porcelanato. 2007. Tese (Doutorado em Ciência e Engenharia de Materiais) - Escola deEngenharia, Universidade Federal do Rio Grande do Norte, Natal, 2007.

SOUZA, C. H. B. Desenvolvimento de argamassas de revestimento com adição do resíduo do polimento do porcelanato. Recife, 2013. Monografia (Trabalho de Conclusão de Curso) - Universidade Federal de Pernambuco, Recife, 2013.

STEINER, L. R. Efeito do rejeito de polimento do porcelanato na fabricação de blocos de concreto de cimento Portland. Criciúma, 2011. Monografia (Especialização em Engenharia Civil) - Pós-Graduação em Engenharia Civil, Universidade do Extremo Sul de Santa Catarina, Criciúma, 2011.

STEINER, L. R.; BERNARDIN, A.; PELISSER, F. Effectiveness of ceramic tile polishing residues as supplementary cementitious materials for cement mortars. SustainableMaterialsand Technologies, v. 4, p. 30-35, 2015.

STEINER, L. R. Efeito do resíduo de polimento de porcelanato como material cimentício suplementar. Criciúma, 2014. Dissertação (Mestrado em Engenharia Civil) - Universidade do Extremo Sul Catarinense, Criciúma, 2014. 
TORRES, D. R.; ROMANO, R. C. O.; PILEGGI, R. G. Influência da variação da velocidade de rotação e do tipo de cimento nas propriedades de argamassas de revestimento nos estados fresco e endurecido. Cerâmica, v. 63 , p. 508-516, 2017.

UYSAL, M; YILMAZ, K. Effect of mineral admixtures on properties of self-compacting concrete. Cement and Concrete Composites, v. 33, p. 771-776, 2011.

WORLD BUSINESS COUNCIL FOR SUSTAINABLE DEVELOPMENT. Cement industry calls for long-term policy certainty as it aspires to reduce CO2 emissions by 20-25\% by 2030. 2015. Disponível em: http://www.wbcsdcement.org/pdf/20151208_press\%20release_LCTPi\%20Cement.pdf. Acesso em: 09 abr. 2017.

\title{
Agradecimentos
}

Os autores agradecem ao CNPq, ao Instituto Federal de Santa Catarina (IFSC) - Campus Florianópolis e ao Instituto Nacional de Tecnologias Cimentícias Ecoeficientes Avançadas (FAPESP INCT 465593/2014-3). Agradecem também a Eliane Revestimentos, a MC-Bauchemie e a Itambé pelas doações dos materiais utilizados nesta pesquisa.

\author{
Andrea Murillo Betioli \\ Departamento Acadêmico de Construção Civil | Instituto Federal de Santa Catarina | Av. Mauro Ramos, 950 | Florianópolis - SC - Brasil | \\ CEP 88020-300 | Tel.: (48) 3211-6060 | E-mail: andrea.betioli@ifsc.edu.br \\ Morgana Fortunato \\ Departamento Acadêmico de Construção Civil | Instituto Federal de Santa Catarina | E-mail: morgana.fortunato.reinert@gmail.com \\ Ben-HurRaíra Martins \\ Departamento Acadêmico de Construção Civil | Instituto Federal de Santa Catarina | E-mail: benhur.r.martins@gmail.com \\ Juliana Machado Casali \\ Departamento Acadêmico de Construção Civil | Instituto Federal de Santa Catarina | E-mail: juliana.casali@ifsc.edu.br \\ Janaíde Cavalcante Rocha \\ Departamento de Engenharia Civil | Universidade Federal de Santa Catarina | Rua João Pio Duarte da Silva, 205 | Florianópolis - SC - \\ Brasil | CEP 88040-900 | Tel.: (48) 3721-5169 | E-mail: janaide.rocha@ufsc.br

\section{Giovana Collodetti} \\ Departamento Acadêmico de Construção Civil | Instituto Federal de Santa Catarina | E-mail: giovana.collodetti@ifsc.edu.br
}

\author{
Ambiente Construído \\ Revista da Associação Nacional de Tecnologia do Ambiente Construído \\ Av. Osvaldo Aranha, $99-3^{\circ}$ andar, Centro \\ Porto Alegre - RS - Brasil$$
\text { CEP } 90035-190
$$ \\ Telefone: +55 (51) 3308-4084 \\ Fax: +55 (51) 3308-4054 \\ www.seer.ufrgs.br/ambienteconstruido \\ E-mail: ambienteconstruido@ufrgs.br
}

(c) () 